\title{
Predicting progression from gestational diabetes to impaired glucose tolerance using peri-delivery data: an observational study
}

\author{
Angela Bengtson ${ }^{1}$, Ana Lucia Espinosa Dice ${ }^{1}$, Melissa Clark $^{1}$, Roee Gutman ${ }^{1}$, Dwight \\ Rouse $^{1}$, and Erika Werner ${ }^{2}$ \\ ${ }^{1}$ Brown University School of Public Health \\ ${ }^{2}$ Warren Alpert Medical School of Brown University
}

November 18, 2021

\begin{abstract}
Objective: To develop a predictive model to identify women with recent gestational diabetes (GDM) most likely to progress to impaired glucose tolerance postpartum. Design: Observational study. Setting: Academic medical center in the United States. Population: Postpartum women with recent GDM, defined by Carpenter-Coustan criteria \& 1-year postpartum HbA1c assessment. Methods: We used lasso regression with k-fold cross validation to develop a multivariable model to predict progression to impaired glucose tolerance, defined as HbA1c [?] 5.7\%, by 1 year postpartum. Predictive ability was assessed by the area under the curve, sensitivity, specificity, positive and negative predictive values. Main Outcome Measures: Impaired glucose tolerance. Results: Of 203 women, $71(35 \%)$ had impaired glucose tolerance at 1 year postpartum. The final model had an AUC of 0.81 (95\% CI 0.74, 0.87) and included eight indicators of weight, body mass index, Hispanic ethnicity, GDM in a prior pregnancy, GDM diagnosis < 24 weeks' gestation, and fasting and 2-hour plasma glucose at 2 days postpartum. A cut-point of [?] 0.24 predicted probability had sensitivity 80\% (95\% CI 69, 89), specificity 58\% (95\% CI 49, 66), PPV 57\% (95\% CI 46,68$)$ and NPV $83 \%(95 \%$ CI 74, 89) to identify women with impaired glucose tolerance at 1 year postpartum. Conclusions: Our predictive model had reasonable ability to predict impaired glucose tolerance around delivery for women with recent GDM. Funding: National Institute of Mental Health and American Diabetes Association. Keywords: gestational diabetes, impaired glucose tolerance, type 2 diabetes prevention; predictive model
\end{abstract}

\section{Introduction}

Gestational diabetes mellitus (GDM), defined as impaired glucose metabolism first identified in pregnancy, complicates an estimated 288,000 pregnancies in the United States annually. ${ }^{1,2}$ Without intervention, an estimated $70 \%$ of women with GDM progress to type 2 diabetes within 10 years of delivery. ${ }^{3}$ Women with GDM are at higher risk for stroke, cardiovascular and liver disease during their lifetime. ${ }^{4-7}$ Current guidelines recommend that women with recent GDM receive an oral glucose tolerance test (OGTT) at 4-12 weeks postpartum and annually thereafter. ${ }^{8,9}$ However, postpartum OGTT completion is less than $50 \% .{ }^{10-13}$ Recently, an OGTT at 2 days postpartum, prior to women being discharged after delivery, was shown to have comparable predictive ability as an OGTT at 4-12 weeks postpartum, with superior completion rates. ${ }^{14}$ Despite this advance, the sensitivity and positive predictive value of an OGTT at either 2 days or 4-12 weeks postpartum to predict progression to impaired glucose tolerance post-partum remains at $50 \%$ or less. This leads to a missed opportunity to identify individuals after delivery most likely to develop type 2 diabetes over their life course. ${ }^{14}$

Predictive models have been used to develop clinical risk scores, such as the FINDRISC Diabetes Risk Score, to identify non-pregnant persons at high risk for progression to types 2 diabetes for follow-up and intervention. ${ }^{15-18}$ These risk scores do not account for glucose metabolism in pregnancy and therefore are 
not applicable to women with recent GDM. In women with GDM, age, body mass index (BMI), race/ ethnicity, family history of type 2 diabetes, and insulin treatment in pregnancy are all correlated with the risk of progressing to pre-diabetes and type 2 diabetes postpartum, ${ }^{1,19,20}$ but have not been integrated into a clinically useful prediction model to identify high risk women at delivery.

To fill this gap, we developed a predictive model using clinical data available around the time of delivery to identify women with GDM in their most recent pregnancy who are at high risk for progression to impaired glucose tolerance by 1 year postpartum.

\section{Methods}

\section{Study Population and Design}

Data for this study come from a prospective cohort study of pregnant women with GDM, diagnosed by a 1-hour glucose challenge test value [?] $200 \mathrm{mg} / \mathrm{dl}$ or by the Carpenter-Coustan criteria for the 3-hour 100-gram OGTT, in care at a single academic medical center in the United States. Details of the study have been published previously. ${ }^{14}$ Briefly, postpartum women with recent GDM were recruited between January 2017 and July 2018 and were eligible for enrollment if they were[?] 18 years of age and fluent in English or Spanish. Women were excluded if they intended to move outside of the state in the coming year, could not tolerate a 75-gram glucose tolerance test (e.g., women with a history of gastric bypass), or had a known hemoglinopathy. At 2 days postpartum, all participants underwent a 2-hour 75-gram OGTT. Participants and their providers were blinded to the results of this OGTT. Postpartum care was otherwise not altered. Women were contacted to receive an OGTT at 4-12 weeks postpartum, in accordance with current clinical guidelines. Participants were followed through 1 year postpartum. In this analysis we included women that had an HbA1C measure at 1 year postpartum (+/- 4 months) to assess glucose metabolism ( $\mathrm{n}=203 / 300$, $68 \%$; Figure 1). All study participants provided written informed consent prior to data collection and ethical approval was provided by the Institutional Review Board Women and Infants Hospital in Providence, Rhode Island (IRB \#836907).

\section{Measures}

The primary outcome was impaired glucose tolerance at 1 year postpartum, defined as a HbA1c [?] $5.7 \%$. We evaluated the number of women with HbA1c [?] 6.5\%, consistent with type 2 diabetes, but did not consider type 2 diabetes as an outcome because of the small number of events. Covariate information for potential predictors of impaired glucose tolerance at 1-year postpartum were collected using surveys at study enrollment, in which women self-identified race-ethnicity, education history, and insurance status, and from electronic medical records, which included information on maternal age, weight and height, prepregnancy BMI, family history of type 2 diabetes, timing of GDM diagnosis and management, and delivery and neonatal complications. Information on plasma glucose values at 2 days postpartum was available for all study participants via study records.

We identified potential predictors known to be associated with progression from GDM to impaired glucose tolerance or type 2 diabetes postpartum based on literature review. ${ }^{21}$ Covariates were considered for inclusion into the predictive model if they were collected during prenatal care or within 2 days of delivery, in order to facilitate identification of women with recent GDM who may be at high risk for progression to impaired glucose tolerance prior to hospital discharge for delivery. Details about all candidate predictors considered are available in Supplemental Table S1. Potentially collinear candidate predictors were considered (e.g. prepregnancy BMI and obesity) to allow the model to select the covariate(s) with the best predictive value. ${ }^{22}$

\section{Statistical Analysis}

We developed a predictive model to identify women with recent GDM around the time of delivery at high risk for developing impaired glucose tolerance by 1 year postpartum. Model development proceeded in several steps. First, to address missing data among potential predictors, we used multiple imputation with chained equations where continuous and count variables were imputed using predictive mean matching ( $\mathrm{n}=30$ imputations). ${ }^{23}$ Second, within each multiply imputed complete dataset we used logistic regression to 
evaluate bivariable associations between each candidate predictor and impaired glucose tolerance. Finally, to develop a parsimonious multivariable model we used Lasso regression with $\mathrm{k}$-fold cross validation $(\mathrm{k}=10$ folds) for covariate selection and combined estimates across multiply imputed datasets using Rubin's rules. ${ }^{23}$ Lasso regression is a predictive modeling approach that allows for principled covariate selection when there is a large number of collinear covariates..$^{22,24}$

A priori we specified that any covariate selected in $>60 \%$ of the imputed datasets would be included in the final multivariable model. ${ }^{29,30}$ The discriminatory ability of each model was assessed by the area under the receiver operating curve (AUC). To evaluate the robustness of the final multivariable model, we performed sensitivity analyses including only participants with complete case and examining how exclusion or inclusion of predictors of type 2 diabetes which may not be available in routine care (e.g. glucose values at 2-days postpartum) or be collinear (e.g. weight and BMI) influenced model results (Supplemental Table S2).

Finally, we evaluated the calibration and predictive ability of the final multivariable model to identify women at high risk for impaired glucose tolerance at 1 year postpartum. To assess model calibration, model predicted probabilities for impaired glucose tolerance were categorized into quartiles, cross-tabulated, and graphed against true event outcomes. ${ }^{31}$ To evaluate model predictive ability, we assessed the sensitivity, specificity, and positive and negative predictive values (PPV, NPV) across a range of predicted probability cut-points to identify women most likely to progress to impaired glucose tolerance by 1 year postpartum. Statistical analyses were performed using Stata 16.1 (StataCorp. 2019. Stata Statistical Software: Release 16 . College Station, TX) and R 4.0.2 (R Core Team. 2020. R: A language and environment for statistical computing . Vienna, Austria: R Foundation for Statistical Computing).

\section{Funding}

This work was supported by the National Institute of Mental Health (grant number R00 MH112413) and the American Diabetes Association (grant number 1-16-ICTS-118). The funding source had no involvement in the study design, analysis or interpretation.

\section{Results}

We included 203 women with an HbA1c measure at 1 year postpartum; of whom 71 (35\%) had impaired glucose tolerance. Nine women (4\%) had HbA1c [?] 6.5\%, consistent with type 2 diabetes at 1 year postpartum. Overall, our cohort was diverse (31\% Hispanic and 10\% non-Hispanic Black), women were overweight (median BMI 29.6; IQR 25.7, 34.9), over half required insulin or medication for GDM management during pregnancy, and $12 \%$ were diagnosed with GDM at $<24$ weeks' gestation (Table 1 ). Hispanic women were over represented among those who developed impaired glucose tolerance ( $48 \%$ with impaired glucose tolerance versus $21 \%$ without), while white women were under-represented ( $32 \%$ with impaired glucose tolerance vs $57 \%$ without). Women who developed impaired glucose tolerance were more likely to report a family history of type 2 diabetes ( $64 \%$ vs $48 \%$ ), be obese pre-pregnancy ( $70 \%$ vs $36 \%$ ), be diagnosed with GDM at $<24$ weeks' gestation ( $23 \%$ vs $6 \%$ ), have experienced GDM in a previous pregnancy (34\% vs 17\%), and require insulin or medication for GDM management in their most recent pregnancy ( $67 \%$ vs $52 \%$ ).

Eight candidate predictors were selected for inclusion into the final multivariable model. They included continuous pre-pregnancy weight, continuous pre-pregnancy BMI, pre-pregnancy obesity (BMI [?] $30 \mathrm{~kg} / \mathrm{m}^{2}$, versus not), GDM in a previous pregnancy (yes versus no or first pregnancy), Hispanic ethnicity (yes versus no), GDM diagnosis before 24 weeks' gestation (yes versus no), and continuous measures of fasting and 2-hour plasma glucose at 2 days postpartum. We a priori specified that candidate predicators would be included into the final model if they were selected by a Lasso model in $>60 \%$ of imputed datasets; however, all but one of the predictors included in the final model were selected in $100 \%$ of imputed data sets (Supplemental Figure S3). The final multivariable model had an AUC of 0.81 (95\% CI 0.74, 0.87; Table 2).

In sensitivity analyses, we examined the robustness of the final multivariable model in several ways. First, we excluded 2-day postpartum glucose data because glucose testing at this time is not standard of care. Second, we removed each of the weight and BMI variables individually to evaluate the impact of having 
highly correlated variables (e.g. weight and BMI) in the final model. Third, we removed the indicator for Hispanic ethnicity since ethnicity is not a reliable indicator of genetic differences and this variable likely captures a complex mix of ethnicity and social processes which may influence Hispanic women's risk of impaired glucose tolerance. ${ }^{25}$ Finally, we replaced Hispanic ethnicity in the final model with family history of type 2 diabetes to evaluate if a more direct measure of genetic risk (e.g. family history) influenced model results. All sensitivity analyses resulted in comparable or slightly reduced AUC compared to the final multivariable model from the primary analysis (Supplemental Table S2).

To identify women with impaired glucose metabolism at 1 year postpartum, we examined several possible cut-points of predicted probabilities from the final multivariable model. A cut-point of 0.13 resulted in a sensitivity of $96 \%$ and specificity of $35 \%, 44 \%$ PPV and $94 \%$ NPV to identify women with impaired glucose tolerance at 1 year postpartum (Table 3; Supplemental Figure S4). This cut point would identify $76 \%$ of the population for potential postpartum intervention, miss predicting impaired glucose tolerance in $2 \%$ of women, and incorrectly predict impaired glucose tolerance in $42 \%$ of women. A cut-point of 0.65 resulted in specificity of $96 \%$, sensitivity of $39 \%$, PPV $8 \%$ and NPV $75 \%$. This cut-point would identify $17 \%$ of the population for additional intervention, miss predicting impaired glucose tolerance in $21 \%$ of women, and incorrectly predict impaired glucose tolerance in $3 \%$ of women.

To assess calibration of the final multivariable model, we compared observed and predicted probabilities of the outcome. Observed and predicted probabilities were similar for women in the lower two quartiles of risk, but were overestimated for women in the highest two quartile or risk, which may indicate model overfitting because of the small number of events in this sample (Supplemental Figure S5). ${ }^{22}$

\section{Discussion}

\section{Main Findings}

Our predictive model for use around the time of delivery demonstrated good discriminatory ability (AUC $0.81 ; 95 \%$ CI $0.74,0.87$ ) and improved prediction over reported OGTT values at 4-12 weeks postpartum (AUC $0.60 ; 95 \%$ CI $0.53,0.67)^{14}$, the current standard of care, to identify women at high risk for postpartum impaired glucose tolerance. Compared to reported values for a postpartum OGTT, our model also demonstrated improved sensitivity, specificity, PPV and NPV at several cut-points to identify women with impaired glucose tolerance by 1 year postpartum. ${ }^{14}$ Our results provide proof of concept that a risk score may be able to accurately identify women with recent GDM around the time of delivery who are likely to progress to impaired glucose tolerance postpartum. With less than $50 \%$ of women with recent GDM receiving any postpartum glucose testing or intervention, ${ }^{10,13}$ identifying high risk women around the time of delivery could help to target follow-up testing and intervention efforts in this high risk population.

Adults with impaired glucose metabolism are at high risk of progressing to type 2 diabetes, making them an important population for early intervention and prevention. ${ }^{26}$ To develop a clinically useful model, we prioritized potential predictors that can be readily collected in the prenatal and early postpartum period, and used a Lasso regression, which is a data-driven predictive modeling algorithm, to select covariates for inclusion in a final model. This algorithm has been used to identify clusters of clinical predictors of progression to type 2 diabetes in non-pregnant populations, ${ }^{27-29}$ but have not been employed in populations with recent GDM. Our final model included eight covariates that are known to correlate with the risk of progression to impaired glucose tolerance in women with GDM including, pre-pregnancy weight and BMI, previous GDM, early GDM diagnosis, Hispanic ethnicity, and fasting and 2-hour plasma glucose at 2 days postpartum. ${ }^{19,25,30-34}$

The predictive ability of the final model did not change meaningfully in several sensitivity analyses, including excluding plasma glucose values at 2 days postpartum, which is not currently standard of care. Model findings were also robust when evaluating the exclusion of collinear weight and BMI covariates within the model, suggesting that while these variables are closely correlated, including both in the model overall improves prediction, rather than adversely affecting the model's performance. Model performance did not change meaningfully when Hispanic ethnicity was removed from the model or replaced with family history of type 


\section{2 diabetes. ${ }^{25}$}

\section{Strengths and Limitations}

This analysis has several strengths and limitations. Strengths include the use of a rich set of covariates from the prenatal and early postpartum period, including glucose metabolism values at 2 days postpartum, robust methods including the use of a predictive modelling algorithm to identify important predictors in the presence of a small number of events and several collinear variables, internal validation with $\mathrm{k}$-fold cross validation, and calibration assessment of the final model. ${ }^{22}$ In addition, we used multiple imputation to address missing covariate data, which is often ubiquitous in routinely collected clinical data. ${ }^{36}$ Limitations include the fact that only $68 \%$ of women from the parent study $(n=300)$ had glucose metabolism assessed at 1 year postpartum and were included in the present analysis, raising the possibility of selection bias. However, a previous analysis of these data indicated that on average, women who returned at 1 year postpartum were similar to women who did not across measured covariates, with the exception of being more likely to be privately insured. ${ }^{14}$ Women in the study were followed for only 1 year postpartum, which is too short to evaluate type 2 diabetes as an outcome. Our analysis also included information on race/ethnicity as a potential predictor of impaired glucose tolerance. Type 2 diabetes is well known to have a genetic component ${ }^{37,38}$. However, race and ethnicity are not reliable indicators of genetic differences. ${ }^{39}$ In this context, race/ethnicity likely represent social rather than genetic differences. We note the lack of additional covariates related to social stratification (socioeconomic status, healthcare access, etc.) as a limitation. Finally, in our calibration analysis we observed some evidence of model overfitting in women in the highest two quartiles of predicted risk, which may reflect the small sample size in our cohort and indicates the need to validate these findings in larger cohorts of women with GDM.

\section{Interpretation}

We evaluated a range of potential cut-points from our predictive model that could be used to prioritize groups of women to target for different interventions. For example, the Diabetes Prevention Program demonstrated that lifestyle modification in women with a history of GDM reduces the risk of type 2 diabetes by $50 \%$, but is costly to implement at $\$ 9,000 /$ year. ${ }^{35}$ For our model, a cut-point of 0.24 would identify $56 \%$ of women for additional intervention and had reasonable sensitivity (80\%) and low specificity (58\%), suggesting it could be a useful cut-point to identify a high risk subgroup of women for the most intensive and costly postpartum lifestyle modification interventions. Conversely, a cut-point of 0.13 would identify $76 \%$ of the population for further intervention, had higher sensitivity (96\%) and lower specificity (35\%) and may be more appropriate for low-cost interventions, such as metformin or other pharmacological interventions. Future cost-effectiveness analyses are required to investigate the implications of offering interventions to women with GDM based on different cut-points from the proposed model.

Our results indicate a clinical prediction model may be useful around the time of delivery to identify women with recent GDM at high risk for impaired glucose tolerance. However, a larger study with longer follow-up is needed to assess the model's ability to predict type 2 diabetes. In addition, future work should explore whether covariates such as socioeconomic status, healthcare access, and diet help to predict type 2 diabetes risk.

\section{Conclusions}

Women with recent GDM are at high risk for progressing to impaired glucose tolerance and eventually type 2 diabetes. Our model prioritized the use of information routinely available or easy to collect as part of routine care and had good predictive ability to identify women at highest risk of progression. Future research should evaluate, refine, and externally validate our model in larger cohorts of women with recent GDM followed for longer periods of time to evaluate the ability to predict type 2 diabetes. If found to be valid and reliable, a predictive model to identify women with recent GDM at highest risk to progress to type 2 diabetes would have important prevention benefits for type 2 diabetes among this high risk population.

Acknowledgements: None declared. 
Disclosure of Interests: None declared.

Contribution to authorship: EW designed the study and oversaw data collection. AMB designed the analysis, with input from ALED and RG, and drafted the initial manuscript. ALED conducted the data analysis and helped with drafting the manuscript. All authors critically reviewed and provided feedback on the final manuscript. AMB takes responsibility for the contents of the article.

Ethics approval: All study participants provided written informed consent prior to data collection and ethical approval was provided by the Institutional Review Board Women and Infants Hospital in Providence, Rhode Island on January 6, 2016. (IRB \#836907)

Funding: This work was supported by the National Institute of Mental Health (grant number R00 MH112413) and the American Diabetes Association (grant number 1-16-ICTS-118).

\section{References}

1. Casagrande SS, Linder B, Cowie CC. Prevalence of gestational diabetes and subsequent Type 2 diabetes among U.S. women. Diabetes Res Clin Pract. 2018;141:200-8.

2. CDC National Center for Health Statistics. Births and Natality: Centers for Disease Control and Prevention, ; 2018 [Available from: https://www.cdc.gov/nchs/fastats/births.htm.

3. Kim C, Newton KM, Knopp RH. Gestational diabetes and the incidence of type 2 diabetes: a systematic review. Diabetes Care. 2002;25(10):1862-8.

4. Kramer CK, Campbell S, Retnakaran R. Gestational diabetes and the risk of cardiovascular disease in women: a systematic review and meta-analysis. Diabetologia. 2019;62(6):905-14.

5. Li J, Song C, Li C, Liu P, Sun Z, Yang X. Increased risk of cardiovascular disease in women with prior gestational diabetes: A systematic review and meta-analysis. Diabetes Res Clin Pract. 2018;140:324-38.

6. Retnakaran R, Luo J, Shah BR. Gestational diabetes in young women predicts future risk of serious liver disease. Diabetologia. 2019;62(2):306-10.

7. Tobias DK, Stuart JJ, Li S, Chavarro J, Rimm EB, Rich-Edwards J, et al. Association of History of Gestational Diabetes With Long-term Cardiovascular Disease Risk in a Large Prospective Cohort of US Women. JAMA Intern Med. 2017;177(12):1735-42.

8. Committee on Practice BO. ACOG Practice Bulletin No. 190: Gestational Diabetes Mellitus. Obstet Gynecol. 2018;131(2):e49-e64.

9. American Diabetes A. 13. Management of Diabetes in Pregnancy: Standards of Medical Care in Diabetes2018. Diabetes Care. 2018;41(Suppl 1):S137-S43.

10. Shah BR, Lipscombe LL, Feig DS, Lowe JM. Missed opportunities for type 2 diabetes testing following gestational diabetes: a population-based cohort study. BJOG. 2011;118(12):1484-90.

11. Werner EF, Has P, Kanno L, Sullivan A, Clark MA. Barriers to Postpartum Glucose Testing in Women with Gestational Diabetes Mellitus. Am J Perinatol. 2019;36(2):212-8.

12. Hunt KJ, Conway DL. Who returns for postpartum glucose screening following gestational diabetes mellitus? Am J Obstet Gynecol. 2008;198(4):404 e1-6.

13. McCloskey L, Bernstein J, Winter M, Iverson R, Lee-Parritz A. Follow-up of gestational diabetes mellitus in an urban safety net hospital: missed opportunities to launch preventive care for women. J Womens Health (Larchmt). 2014;23(4):327-34.

14. Werner EF, Has P, Rouse D, Clark MA. Two day post-partum compared to 4-12 week post-partum glucose tolerance testing for women with gestational diabetes. Am J Obstet Gynecol. 2020. 
15. Lindström J, Tuomilehto J. The diabetes risk score: a practical tool to predict type 2 diabetes risk. Diabetes Care. 2003;26(3):725-31.

16. Schmidt MI, Duncan BB, Bang H, Pankow JS, Ballantyne CM, Golden SH, et al. Identifying individuals at high risk for diabetes: The Atherosclerosis Risk in Communities study. Diabetes Care. 2005;28(8):2013-8.

17. Stern MP, Williams K, Haffner SM. Identification of persons at high risk for type 2 diabetes mellitus: do we need the oral glucose tolerance test? Ann Intern Med. 2002;136(8):575-81.

18. Wilson PW, Meigs JB, Sullivan L, Fox CS, Nathan DM, D'Agostino RB, Sr. Prediction of incident diabetes mellitus in middle-aged adults: the Framingham Offspring Study. Arch Intern Med. 2007;167(10):1068-74.

19. Rayanagoudar G, Hashi AA, Zamora J, Khan KS, Hitman GA, Thangaratinam S. Quantification of the type 2 diabetes risk in women with gestational diabetes: a systematic review and meta-analysis of 95,750 women. Diabetologia. 2016;59(7):1403-11.

20. Retnakaran R, Qi Y, Sermer M, Connelly PW, Hanley AJ, Zinman B. Glucose intolerance in pregnancy and future risk of pre-diabetes or diabetes. Diabetes Care. 2008;31(10):2026-31.

21. Bengtson AM, Ramos SZ, Savitz DA, Werner EF. Risk Factors for Progression From Gestational Diabetes to Postpartum Type 2 Diabetes: A Review. Clin Obstet Gynecol. 2021;64(1):234-43.

22. Pavlou M, Ambler G, Seaman SR, Guttmann O, Elliott P, King M, et al. How to develop a more accurate risk prediction model when there are few events. Bmj. 2015;351:h3868.

23. Rubin DB. Multiple imputation for nonresponse in surveys. New York, New York: Wiley; 1987.

24. Hastie T, Tibshirani R, Friedman J. The Elements of Statistical Learning: Data Mining, Inference, and Prediction: Springer New York; 2013.

25. Xiang AH, Li BH, Black MH, Sacks DA, Buchanan TA, Jacobsen SJ, et al. Racial and ethnic disparities in diabetes risk after gestational diabetes mellitus. Diabetologia. 2011;54(12):3016-21.

26. Nathan DM, Davidson MB, DeFronzo RA, Heine RJ, Henry RR, Pratley R, et al. Impaired fasting glucose and impaired glucose tolerance: implications for care. Diabetes Care. 2007;30(3):753-9.

27. Zaharia OP, Strassburger K, Strom A, Bönhof GJ, Karusheva Y, Antoniou S, et al. Risk of diabetesassociated diseases in subgroups of patients with recent-onset diabetes: a 5-year follow-up study. The lancet Diabetes \& endocrinology. 2019;7(9):684-94.

28. Dennis JM, Shields BM, Henley WE, Jones AG, Hattersley AT. Disease progression and treatment response in data-driven subgroups of type 2 diabetes compared with models based on simple clinical features: an analysis using clinical trial data. The lancet Diabetes \& endocrinology. 2019;7(6):442-51.

29. Ahlqvist E, Storm P, Käräjämäki A, Martinell M, Dorkhan M, Carlsson A, et al. Novel subgroups of adult-onset diabetes and their association with outcomes: a data-driven cluster analysis of six variables. The lancet Diabetes \& endocrinology. 2018;6(5):361-9.

30. Bao W, Yeung E, Tobias DK, Hu FB, Vaag AA, Chavarro JE, et al. Long-term risk of type 2 diabetes mellitus in relation to BMI and weight change among women with a history of gestational diabetes mellitus: a prospective cohort study. Diabetologia. 2015;58(6):1212-9.

31. Golden SH, Bennett WL, Baptist-Roberts K, Wilson LM, Barone B, Gary TL, et al. Antepartum glucose tolerance test results as predictors of type 2 diabetes mellitus in women with a history of gestational diabetes mellitus: a systematic review. Gend Med. 2009;6 Suppl 1:109-22.

32. Katon J, Williams MA, Reiber G, Miller E. Antepartum A1C, maternal diabetes outcomes, and selected offspring outcomes: an epidemiological review. Paediatr Perinat Epidemiol. 2011;25(3):265-76. 
33. Buchanan TA, Xiang A, Kjos SL, Lee WP, Trigo E, Nader I, et al. Gestational diabetes: antepartum characteristics that predict postpartum glucose intolerance and type 2 diabetes in Latino women. Diabetes. 1998;47(8):1302-10.

34. Löbner K, Knopff A, Baumgarten A, Mollenhauer U, Marienfeld S, Garrido-Franco M, et al. Predictors of postpartum diabetes in women with gestational diabetes mellitus. Diabetes. 2006;55(3):792-7.

35. van der Heijden GJ, Donders AR, Stijnen T, Moons KG. Imputation of missing values is superior to complete case analysis and the missing-indicator method in multivariable diagnostic research: a clinical example. Journal of clinical epidemiology. 2006;59(10):1102-9.

36. Li M, Rahman ML, Wu J, Ding M, Chavarro JE, Lin Y, et al. Genetic factors and risk of type 2 diabetes among women with a history of gestational diabetes: findings from two independent populations. BMJ Open Diabetes Research and Care. 2020;8(1).

37. Udler MS, Kim J, von Grotthuss M, Bonàs-Guarch S, Cole JB, Chiou J, et al. Type 2 diabetes genetic loci informed by multi-trait associations point to disease mechanisms and subtypes: A soft clustering analysis. PLoS Med. 2018;15(9):e1002654.

38. Vyas DA, Eisenstein LG, Jones DS. Hidden in Plain Sight - Reconsidering the Use of Race Correction in Clinical Algorithms. N Engl J Med. 2020;383(9):874-82.

39. Ratner RE, Christophi CA, Metzger BE, Dabelea D, Bennett PH, Pi-Sunyer X, et al. Prevention of diabetes in women with a history of gestational diabetes: effects of metformin and lifestyle interventions. The Journal of clinical endocrinology and metabolism. 2008;93(12):4774-9.

\section{Tables}

Table 1: Clinical characteristics from pre-pregnancy and delivery among 203 women with gestational diabetes mellitus (GDM) in their most recent pregnancy by impaired glucose metabolism status at 1 year postpartum.

\begin{tabular}{lll}
\hline Characteristic & Characteristic & Normal HbA1c at 1 year $\mathbf{~}$ \\
\hline \multirow{2}{*}{ Demographic and clinical characteristics } & & Median (IQR) \\
& Maternal age (years) & $32(29,36)$ \\
& Gravidity & $2(1.5,3)$ \\
& Gestational age at first prenatal visit & $9(8,11)$ \\
& Gestational age at delivery & $39(38,39)$ \\
Education & & $\mathrm{n}(\%)$ \\
& Less than secondary & $11(8.5 \%)$ \\
Race & Secondary or higher & $119(91.5 \%)$ \\
& White & $75(56.8 \%)$ \\
& Non-Hispanic Black & $14(10.6 \%)$ \\
LGA neonate & Hispanic & $28(21.2 \%)$ \\
& Other & $15(11.4 \%)$ \\
Family History of DM & No & $7(5.3 \%)$ \\
Previous GDM & Yes & $125(94.7 \%)$ \\
& No & $58(52.3 \%)$ \\
Pre-pregnancy BMI $(\mathrm{kg} / \mathrm{m} 2)$ & Yes & $53(47.8 \%)$ \\
& Gravidity $=1$ & $33(25.0 \%)$ \\
& Gravidity $>1$, no previous GDM & $76(57.6 \%)$ \\
& Gravidity $>1$, previous $G D M$ & $23(17.4 \%)$ \\
& Underweight & $1(0.8 \%)$ \\
& Normal & $35(26.7 \%)$ \\
& Overweight & $48(36.6 \%)$
\end{tabular}




\begin{tabular}{lll}
\hline Characteristic & Characteristic & Normal HbA1c at 1 year $\mathbf{~}$ \\
\hline \multirow{3}{*}{ GDM diagnosis $<24$ wk gestation } & Obese & $47(35.9 \%)$ \\
& No & $121(93.8 \%)$ \\
Gestational Weight Gain Category & Yes & $8(6.2 \%)$ \\
& In Range & $39(35.5 \%)$ \\
& Above Range & $36(32.7 \%)$ \\
Took Insulin or Medication for GDM Management & Below Range & $35(31.8 \%)$ \\
& No & $64(48.5 \%)$ \\
LGA neonate & Yes & $68(51.5 \%)$ \\
& Yes & $7(5.3 \%)$ \\
& & $125(94.7 \%)$ \\
\hline
\end{tabular}

Table 2: Bivariable and Multivariable Logistic Regression Results for Predicting of Impaired Glucose Metabolism at 1 Year Postpartum.

\begin{tabular}{|c|c|c|c|c|c|}
\hline & & $\begin{array}{l}\text { Individual } \\
\text { Predictors }\end{array}$ & $\begin{array}{l}\text { Individual } \\
\text { Predictors }\end{array}$ & $\begin{array}{l}\text { Combined } \\
\text { Predictors }\end{array}$ & $\begin{array}{l}\text { Combined } \\
\text { Predictors }\end{array}$ \\
\hline & & Bivariable & Bivariable & Multivariate & Multivariate \\
\hline & & Logistic & Logistic & Logistic & Logistic \\
\hline & & Regression & Regression & Regression & Regression \\
\hline & & Results ${ }^{*}$ & Results ${ }^{*}$ & Results $^{+}$ & Results $^{+}$ \\
\hline \multirow[t]{2}{*}{ Time Period } & Predictor & OR $(95 \%$ & AUC $(95 \%$ & OR $(95 \%$ & AUC $(95 \%$ \\
\hline & & CI) & CI) & CI) & CI) \\
\hline Prenatal & $\begin{array}{l}\text { Pre-pregnancy } \\
\text { weight, } \\
\text { continuous }\end{array}$ & $\begin{array}{l}1.02(1.01, \\
1.02)\end{array}$ & $\begin{array}{l}0.71(0.64, \\
0.78)\end{array}$ & $\begin{array}{l}1.01(0.99, \\
1.03)\end{array}$ & $\begin{array}{l}0.81(0.74 \\
0.87)\end{array}$ \\
\hline Prenatal & $\begin{array}{l}\text { BMI } \\
\text { pre-pregnancy, } \\
\text { continuous }\end{array}$ & $1.11(1.07,1.17)$ & $0.72(0.65,0.80)$ & $1.01(0.89,1.14)$ & \\
\hline Prenatal & $\begin{array}{l}\text { Pre-pregnancy } \\
\text { obesity (BMI } \\
\text { [?] 30) vs. not }\end{array}$ & $\begin{array}{l}4.31(2.31, \\
8.02)\end{array}$ & $\begin{array}{l}0.67(0.61 \\
0.74)\end{array}$ & $\begin{array}{l}1.37(0.46, \\
4.05)\end{array}$ & \\
\hline Prenatal & $\begin{array}{l}\text { Previous GDM } \\
\text { gravidity }>1 \& \\
\text { had GDM } \\
\text { previously vs. } \\
\text { not }\end{array}$ & $\begin{array}{l}2.42(1.24, \\
4.71)\end{array}$ & $\begin{array}{l}0.58(0.52, \\
0.65)\end{array}$ & $\begin{array}{l}1.53(0.68, \\
3.44)\end{array}$ & \\
\hline Prenatal & $\begin{array}{l}\text { Hispanic vs. } \\
\text { not }\end{array}$ & $\begin{array}{l}3.41(1.83, \\
6.38)\end{array}$ & $\begin{array}{l}0.63(0.57 \\
0.70)\end{array}$ & $\begin{array}{l}3.44(1.59, \\
7.47)\end{array}$ & \\
\hline Prenatal & $\begin{array}{l}\text { GDM } \\
\text { diagnosis }<24 \\
\text { weeks GA vs. } \\
\text { not }\end{array}$ & $\begin{array}{l}3.98(1.66, \\
9.55)\end{array}$ & $\begin{array}{l}0.58(0.53 \\
0.63)\end{array}$ & $\begin{array}{l}2.05(0.72, \\
5.83)\end{array}$ & \\
\hline $\begin{array}{l}2 \text { days } \\
\text { postpartum }\end{array}$ & $\begin{array}{l}\text { Fasting } \\
\text { Plasma } \\
\text { Glucose, } \\
\text { continuous }\end{array}$ & $\begin{array}{l}1.06(1.03, \\
1.09)\end{array}$ & $\begin{array}{l}0.65(0.57 \\
0.74)\end{array}$ & $\begin{array}{l}1.04(1.01, \\
1.07)\end{array}$ & \\
\hline $\begin{array}{l}2 \text { days } \\
\text { postpartum }\end{array}$ & $\begin{array}{l}\text { 2-hour Plasma } \\
\text { Glucose, } \\
\text { continuous }\end{array}$ & $\begin{array}{l}1.01(1.01, \\
1.02)\end{array}$ & $\begin{array}{l}0.64(0.56, \\
0.72)\end{array}$ & $\begin{array}{l}1.01(1.00, \\
1.02)\end{array}$ & \\
\hline
\end{tabular}




\begin{tabular}{|c|c|c|c|c|c|}
\hline & & $\begin{array}{l}\text { Individual } \\
\text { Predictors }\end{array}$ & $\begin{array}{l}\text { Individual } \\
\text { Predictors }\end{array}$ & $\begin{array}{l}\text { Combined } \\
\text { Predictors }\end{array}$ & $\begin{array}{l}\text { Combined } \\
\text { Predictors }\end{array}$ \\
\hline * Bivariable & ${ }^{*}$ Bivariable & ${ }^{*}$ Bivariable & ${ }^{*}$ Bivariable & ${ }^{*}$ Bivariable & ${ }^{*}$ Bivariable \\
\hline Results $=$ & Results $=$ & Results $=$ & Results $=$ & Results $=$ & Results $=$ \\
\hline Bivariate & Bivariate & Bivariate & Bivariate & Bivariate & Bivariate \\
\hline logistic & logistic & logistic & logistic & logistic & logistic \\
\hline $\mathrm{M}=30$ & $\mathrm{M}=30$ & $\mathrm{M}=30$ & $\mathrm{M}=30$ & $\mathrm{M}=30$ & $\mathrm{M}=30$ \\
\hline multiply & multiply & multiply & multiply & multiply & multiply \\
\hline imputed & imputed & imputed & imputed & imputed & imputed \\
\hline datasets & datasets & datasets & datasets & datasets & datasets \\
\hline combined with & combined with & combined with & combined with & combined with & combined with \\
\hline Final & Final & Final & Final & Final & Final \\
\hline multivariate & multivariate & multivariate & multivariate & multivariate & multivariate \\
\hline logistic & logistic & logistic & logistic & logistic & logistic \\
\hline regression on & regression on & regression on & regression on & regression on & regression on \\
\hline $\mathrm{M}=30$ & $\mathrm{M}=30$ & $\mathrm{M}=30$ & $\mathrm{M}=30$ & $\mathrm{M}=30$ & $\mathrm{M}=30$ \\
\hline multiply & multiply & multiply & multiply & multiply & multiply \\
\hline imputed & imputed & imputed & imputed & imputed & imputed \\
\hline datasets & datasets & datasets & datasets & datasets & datasets \\
\hline combined with & combined with & combined with & combined with & combined with & combined with \\
\hline Rubin's Rules & Rubin's Rules & Rubin's Rules & Rubin's Rules & Rubin's Rules & Rubin's Rules \\
\hline
\end{tabular}

Table 3: Ability to Predict Impaired Glucose Metabolism, defined as HbA1C [?]5.7\%, at 1 Year Postpartum by Predicted Probability Cut-point

\begin{tabular}{|c|c|c|c|c|c|c|c|}
\hline $\begin{array}{l}\text { Cut- } \\
\text { point }\end{array}$ & $\begin{array}{l}\text { Sensitivity, } \\
\%(95 \% \\
\text { CI })^{*}\end{array}$ & $\begin{array}{l}\text { Specificity, } \\
\%(95 \% \\
\text { CI })\end{array}$ & $\begin{array}{l}\text { Positive } \\
\text { predic- } \\
\text { tive } \\
\text { value, \% } \\
(95 \% \mathrm{CI})\end{array}$ & $\begin{array}{l}\text { Negative } \\
\text { predic- } \\
\text { tive } \\
\text { value, \% } \\
(95 \% \mathrm{CI})\end{array}$ & $\begin{array}{l}\text { Proportion } \\
\text { of the } \\
\text { popula- } \\
\text { tion } \\
\text { identified } \\
\text { by the } \\
\text { risk } \\
\text { score for } \\
\text { interven- } \\
\text { tion, } \\
\%\end{array}$ & $\begin{array}{l}\text { Proportion } \\
\text { of the } \\
\text { popula- } \\
\text { tion the } \\
\text { risk } \\
\text { score in- } \\
\text { correctly } \\
\text { pre- } \\
\text { dicted } \\
\text { event, \% }\end{array}$ & $\begin{array}{l}\text { Proportion } \\
\text { of the } \\
\text { popula- } \\
\text { tion the } \\
\text { risk } \\
\text { score } \\
\text { missed } \\
\text { predict- } \\
\text { ing an } \\
\text { event, \% }\end{array}$ \\
\hline [?] 0.13 & $\begin{array}{l}95.77(88.14, \\
99.12)\end{array}$ & $\begin{array}{l}34.85(26.77 \\
43.63)\end{array}$ & $\begin{array}{l}44.16(36.17 \\
52.37)\end{array}$ & $\begin{array}{l}93.88(83.13, \\
98.72)\end{array}$ & 75.86 & 42.36 & 1.48 \\
\hline$[?] \quad 0.20$ & $\begin{array}{l}90.14(80.74, \\
95.94)\end{array}$ & $\begin{array}{l}51.52(42.66 \\
60.30)\end{array}$ & $\begin{array}{l}50.00(41.04, \\
58.96)\end{array}$ & $\begin{array}{l}90.67(81.71 \\
96.16)\end{array}$ & 63.05 & 31.53 & 3.45 \\
\hline$[?] \quad 0.24$ & $\begin{array}{l}80.28(69.14, \\
88.78)\end{array}$ & $\begin{array}{l}57.58(48.68 \\
66.13)\end{array}$ & $\begin{array}{l}50.44(40.88 \\
59.98)\end{array}$ & $\begin{array}{l}84.44(75.28 \\
91.23)\end{array}$ & 55.67 & 27.59 & 6.90 \\
\hline$[?] \quad 0.33$ & $\begin{array}{l}71.83(59.90 \\
81.87)\end{array}$ & $\begin{array}{l}71.21(62.69 \\
(78.76)\end{array}$ & $\begin{array}{l}57.30(46.37 \\
67.74)\end{array}$ & $\begin{array}{l}82.46(74.21, \\
88.94)\end{array}$ & 43.84 & 18.72 & 9.85 \\
\hline
\end{tabular}




\begin{tabular}{|c|c|c|c|c|c|c|c|}
\hline $\begin{array}{l}\text { Cut- } \\
\text { point }\end{array}$ & $\begin{array}{l}\text { Sensitivity, } \\
\%(95 \% \\
\text { CI })^{*}\end{array}$ & $\begin{array}{l}\text { Specificity, } \\
\%(95 \% \\
\text { CI })\end{array}$ & $\begin{array}{l}\text { Positive } \\
\text { predic- } \\
\text { tive } \\
\text { value, \% } \\
(95 \% \mathrm{CI})\end{array}$ & $\begin{array}{l}\text { Negative } \\
\text { predic- } \\
\text { tive } \\
\text { value, \% } \\
(95 \% \mathrm{CI})\end{array}$ & $\begin{array}{l}\text { Proportion } \\
\text { of the } \\
\text { popula- } \\
\text { tion } \\
\text { identified } \\
\text { by the } \\
\text { risk } \\
\text { score for } \\
\text { interven- } \\
\text { tion, } \\
\%\end{array}$ & $\begin{array}{l}\text { Proportion } \\
\text { of the } \\
\text { popula- } \\
\text { tion the } \\
\text { risk } \\
\text { score in- } \\
\text { correctly } \\
\text { pre- } \\
\text { dicted } \\
\text { event, \% }\end{array}$ & $\begin{array}{l}\text { Proportion } \\
\text { of the } \\
\text { popula- } \\
\text { tion the } \\
\text { risk } \\
\text { score } \\
\text { missed } \\
\text { predict- } \\
\text { ing an } \\
\text { event, \% }\end{array}$ \\
\hline [?] 0.40 & $\begin{array}{l}67.61(55.45 \\
78.24) \%\end{array}$ & $\begin{array}{l}80.30(72.49 \\
86.71)\end{array}$ & $\begin{array}{l}64.86(52.89 \\
75.61)\end{array}$ & $\begin{array}{l}82.17(74.46 \\
88.35)\end{array}$ & 36.45 & 12.81 & 11.33 \\
\hline [?] 0.55 & $\begin{array}{l}52.11(39.92 \\
64.12)\end{array}$ & $\begin{array}{l}90.15(83.75 \\
94.65)\end{array}$ & $\begin{array}{l}74.00(59.66 \\
85.37)\end{array}$ & $\begin{array}{l}77.78(70.36 \\
84.09)\end{array}$ & 24.63 & 6.40 & 16.75 \\
\hline [?] 0.65 & $\begin{array}{l}39.44(28.03 \\
51.75)\end{array}$ & $\begin{array}{l}95.45(90.37 \\
98.31)\end{array}$ & $\begin{array}{l}82.35(65.47 \\
93.24)\end{array}$ & $\begin{array}{l}74.56(67.30 \\
80.93)\end{array}$ & 16.75 & 2.96 & 21.18 \\
\hline
\end{tabular}

* $95 \%$ confidence intervals are calculated using the normal approximation method of the binomial CI, based on the predicted probabilities derived using Rubin's Rules, $\mathrm{z}_{1-\alpha / 2}=1.96, \mathrm{~N}=203$, $\mathrm{n}$ dependent on the estimate of interest, and p equal to the point estimate of the proportion of interest.

Figure Legends

Figure 1 : Study Population Flow Chart

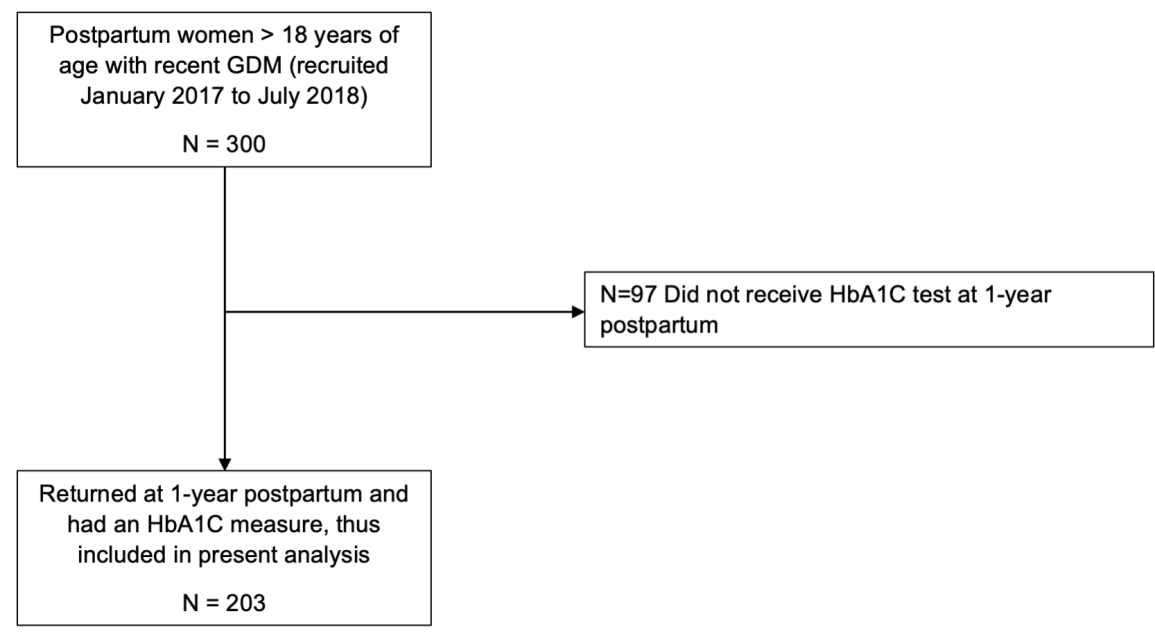

